\title{
Suggestions on the Fiscal and Taxation Policies of Ecological Agriculture in Heilongjiang Province under Green Poverty Alleviation
}

\author{
Lingling Qin ${ }^{1,2, a}$ and Yushuai Zuo $0^{2, b}$ \\ ${ }^{1}$ School of Public Finance and Administration, Harbin University of Commerce,No.1,Xuehai Street, \\ Songbei District, Harbin City, Heilongjiang Province, China \\ ${ }^{2}$ School of Investment and Insurance, Harbin Finance University,No.65,Diantan Road, Xiangfang \\ District, Harbin City, Heilongjiang Province, China

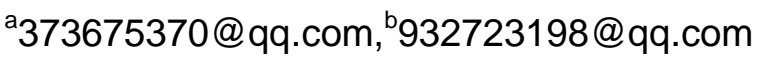

\begin{abstract}
Keywords: Precise poverty alleviation; Green development; Green poverty alleviation; Ecological agriculture
\end{abstract}

\begin{abstract}
With economic development, China's crucial task of tackling poverty and building a well-off society in an all-round way has entered the deciding period. The injection of the concept of green development into the practice of precision poverty reduction is of great significance to the sustainable development of impoverished areas. As a change of development mode, green poverty alleviation has undergone four stages: empowerment theory, sustainable development theory, endogenous development theory and participatory development theory. The specific measures in green poverty alleviation in Heilongjiang Province include accelerating the top-level design of green poverty alleviation, insisting on optimizing green industrial structure, vigorously implementing ecological protection, transferring employment and alleviating poverty, adhering to the combination of poverty alleviation and development and green eco-protection construction, implementing education poverty alleviation projects and implementing Social security has gone all out and so on. The poor farmers have benefited greatly from this, and the industrial structure has been obviously optimized. As a result, the target rate of poverty alleviation has been raised and remarkable changes have taken place in the concept of development. However, green poverty alleviation process still exists the problems of weak infrastructure, labor force outflow and backward concepts, low level of mechanization and so on. As the main policy tool of green poverty alleviation, finance should do a good job of helping the poor precisely by standardizing the special funds for finance, speeding up the hematopoietic function of finance, strengthening the supervision of financial funds, and enhancing the efficiency of the use of fiscal funds.
\end{abstract}

\section{Introduce}

In November 2013, Present Xi first proposed precise poverty alleviation in his visit to Hunan Provinces: poverty alleviation should be realistic and according to local conditions. The concept of "green development" being put forward by the Fifth Plenary Session of the CPC Central Committee is not only a new concept of development and mode of development, but also a powerful driving force for precisely alleviating poverty and for building an overall well-to-do society. Therefore, in the critical period of poverty alleviation and building an overall well-to-do society in China, "injecting" the concept of green development into the practice of precision poverty alleviation can both promote poverty alleviation in poverty-stricken areas and lead the poverty-stricken areas towards green and sustainable development. Combining precise poverty alleviation and green development, many scholars call it green poverty alleviation. Heilongjiang Province is located in the Northeast Plain. With rich cultivated land, rich fertile soil, numerous rivers, abundant water resources and complete biological chain, Heilongjiang Province is well suited to the development of ecological agriculture. Heilongjiang Province, as a food production base in China, occupies a comparative advantage in agricultural development. Therefore, eco-agriculture The development in Heilongjiang is likely to become a reality. 


\section{The Concept of Green Poverty Alleviation and Its Theoretical Evolution}

Green Poverty Alleviation is essentially a shift in development mode. It is a shift from taking economic development as the center to eco-development as the center. It is the deepening development of poverty alleviation and development from "flood irrigation" to "drip irrigation" and from "blood transfusion" to "blood generation". Judging from the theoretical evolution of development, it has undergone four stages of development: empowerment theory, sustainable development theory, endogenous development theory and participatory development theory.

Empowerment theory is mainly reflected in four aspects: First, make the poor groups become the main body of poverty alleviation; second, through the empowerment to achieve the source of external poverty alleviation resources, the main body of poverty alleviation determine development projects and arrange the distribution of public goods according to their own needs so that poverty alleviation resources are really entering the village; third, give the poor groups the opportunity and power to develop; fourth, give the poor the right to independently make decisions, manage resources and distribute profits. The most important contribution of sustainable development theory to poverty eradication is taking into account the accumulated causality in poverty, environmental damage and underdevelopment. The theory of endogenous development comes from two aspects: the result of the role of internal factors in the region and the promotion of external factors. The essence of participatory poverty alleviation is "self-organization, identifying needs, formulating plans and taking action".

\section{Specific Measures and Evaluation of Green Poverty Alleviation in Heilongjiang Province}

Specific Measures to Help the Poor. First, Speeding up the top-level design of Green Poverty Alleviation in Heilongjiang Province. Heilongjiang Province has formulated specific implementation plans, carried out the top-level design, and promulgated a series of guidelines and policies. This not only sets concrete implementation steps, specific targets for assistance, and focuses of work for green pro-poor, but also specifies the direction of development.

Second, adhere to optimize the green industry structure. Structural poverty is the root cause of poor households in poor areas of Heilongjiang Province. Accelerating the adjustment of industrial structure and solving the single industrial structure and income structure are the fundamental solutions to the economic development in poor areas. Since 2001, Heilongjiang Province has made every effort to achieve organic integration of the three-component structure of grain, economy and feeding with the allocation of resources and the coordinated development of primary, secondary and tertiary industries. Vigorously develop animal husbandry, speed up the development of green and specialty industries, and comprehensively optimize the quality of agricultural products. By 2016, gradually implement the development of leading industries with county characteristics, implement the "one village, one product" industry action, support the new type of agricultural management entities to drive poverty alleviation and establish a mechanism for profit-making of industrial assets.

Third, vigorously implement the ecological protection and transfer employment to get rid of poverty. Since 2001,Heilongjiang has insisted on the combination of poverty alleviation and poverty alleviation in-situ development and speeded up the transfer of labor in poor areas. Key counties should pay attention to the export of labor services, actively organize and guide the orderly flow of labor force in impoverished areas, form labor export pairs with developed areas and carry out extensive labor service cooperation. So far, the ways to lift the labor force out of poverty include directing labor export and transfer employment, relying on urbanization to promote transfer of employment and transferring of employment in combination with ecological protection. The transfer of ecological protection includes increasing the area of returning farmland to forestry, returning farmland to grassland, protection of natural forests, construction of shelterbelts, comprehensive management of sloping farmland, water ecological management, wetland protection and restoration, etc.

Fourth, adhere to the combination of poverty alleviation and green ecological protection. The deterioration of the ecological environment is an important obstacle to poverty alleviation in 
poverty areas. Poverty alleviation and development can not be at the cost of sacrificing the ecological environment. It is necessary to earnestly strengthen the protection of forestland, grassland and wetland resources in impoverished areas. We resolutely put an end to the indiscriminate and indiscriminate deforestation, and speed up the process of returning farmland to forests, returning grass and returning wetlands, and restore the ecological environment.

Fifth, Implement education poverty alleviation project. Education funds tilt to basic education in poor areas. We should rationally lay out rural primary and secondary schools in impoverished areas, comprehensively improve basic conditions for running schools, strengthen the construction of boarding schools and increase the rate of compulsory education. we continue to implement the second phase of the pre-school three-year plan of action. erecting pre-school education subsidy system to help poor families receive pre-school children. We will comprehensively implement the plan to improve student nutrition in rural compulsory education in impoverished areas. We should give subsidies to poor families, primary and secondary students, and deal with high school students in poor families exemption tuition and fees. We will strengthen the construction of working-class dormitories for rural teachers and fully implement the policy of subsidies for living allowances for rural teachers in areas with special difficulties.

Sixth, implement social security. One is the implementation of medical security and medical assistance. Heilongjiang Province implemented health poverty alleviation projects in 2016 to prevent poverty caused by illness or returning to poverty due to illness. New rural cooperative medical insurance system and major illness insurance system impose policies on the poor population tilt. The poor people participate in the new type of rural cooperative medical insurance and the individual contributions are subsidized by the government. All the poor people are included in the medical assistance and major diseases. The second is the implementation of rural minimum living security system. We improve rural minimum living security system, and implement comprehensive relief to solve the poor households eat, live, study, medicine and other difficulties. We implement policy support for families that can not rely on industrial support and employment to help alleviate poverty. The third is improving the care service system for left-behind children in rural areas, women, the elderly and the disabled. We should conduct a comprehensive and thorough investigation of the "three left behind" personnel and disabled persons in rural areas and establish a detailed and dynamic information management system.

The Effectiveness of Green Poverty Alleviation. Poor farmers benefit more. We guide poor farmers to develop characteristic industries and connect enterprises' cooperatives to ensure the increase of farmers' income. Pilot village farmers voluntarily changed their economy as industrial economy, effectively solving a series of social problems such as open village, left-behind children and empty-nesters. Effectively solve the problem of barren wasteland. Poor farmers income significantly. The number of poor people is decreasing.

Industrial structure optimization is obvious. From the comparative analysis of relevant documents, we can clearly feel that the optimization and upgrading of industrial structure in Heilongjiang Province is obvious and the development of ecological agriculture has an important advantage.

Improve the targeting rate of poverty alleviation work. Because we have signed an order contract with one household, worked out plans to help them, and accounted measures to support the household funds according to production (area), we targeted anti-poverty funds for the project, targeted assistance to poor households and ensured that $100 \%$ of the funds for assistance were implemented to the poor and improved the targeting rate of anti-poverty work.

The concept of development of poor farmers and enterprises (cooperatives) has undergone fundamental changes. The poor peasants turned themselves into passive participation and took the initiative to participate in industrial development, from passive acceptance of the project arrangement to the active selection of project development, from the project to the initiative to contact the enterprise (cooperative).

Problems in Green Poverty Alleviation. Infrastructure is weak. Heilongjiang Province has a long winter time and short working hours, resulting in imperfect infrastructure construction such as 
highways and high-speed rail lines, which severely constrain the green reduction in the region. At the same time, natural disasters such as dryness, drought, water logging, frost and freezing occur frequently in Heilongjiang Province. The soil erosion in the poor areas is serious, and the content of soil organic matter is decreased, the more hard the floor, the more inability to improve the output capacity.

Labor outflow and lagging ideas restrict poverty alleviation. With the economic development, a large number of rural laborers in Heilongjiang Province flowed to cities, resulting in a heavier load on urban areas and a more benign employment situation. Agricultural land resources are idle, and the quality of the left-behind laborers is declining, and the vacancies of new-type peasants become increasingly prominent. The problem of "emptying the land in rural areas" has become increasingly prominent. The level of rural urbanization lags behind and the gap between urban and rural areas further widens. In the meantime, the farmers in Heilongjiang province are eager to get rich, and the environmental protection concept is backward and the consciousness is shallow, so the exploration of the path of green poverty alleviation has created great pressure.

Low level of mechanization. Heilongjiang province agriculture is divided into the reclamation area and the non-reclamation area, Land reclamation area of contiguous production management, agricultural mechanization level is higher. Non-reclamation areas, especially in poor areas, the mechanization level is relatively low.

Fine management can not achieve the expected results. Fine management is the technical approach that managers use to adjust their products, services, and operations. With the accelerated pace of poverty alleviation projects, some fragile public interest chains are prominent. In production operation and maintenance, we especially need to pay attention to fine management. As a result of various factors, compared with the national counterparts, the cost gap is far apart, so we need more refined management to reduce the cost. The company needs high quality of agricultural products for the development of new agricultural products, and we need refined management more.

Environmental law enforcement attention is not enough. On the one hand, there are loopholes in the environmental protection system and law enforcement methods in Heilongjiang Province, and the role of marketization has not been fully reflected. Due to the economic development of local governments, the lack of emphasis on the enforcement of environmental protection has led to their pollution levels not being effectively contained in many places. On the other hand, poor rural areas have inadequate cultural heritage and are affected by traditional lifestyles, so most peasant masses hold indifferent attitudes toward environmental awareness and ecological civilization from time to time.

\section{Suggestions on Speeding up the Financial Policy of Green Poverty Alleviation in Heilongjiang Province.}

Standardize Unified Financial Special Funds. The author thinks that we want to balance the special funds and avoid the use of repeated subsidies. We should use every cent of the funds in the most needed places, and we should do the following: First, we will set up a special green poverty alleviation agency to focus on targeted poverty alleviation work. The second is to establish a precise poverty alleviation program. All departments will be responsible for the poverty alleviation program subsidies unified collection by the Poverty Alleviation Office for special statistics. We will maximize the funds for the most needed financial support projects and all-round protection of infrastructure construction in poor villages, industrial support, education and training, and other aspects of funding needs, narrowing the gap between education in poverty-stricken areas and the more developed areas in education, health, culture and social security so as to effectively raise the living standards of villagers. third is to develop the appropriate policies and regulations.

Speed up the Financial "Blood" Function. The author believes that in order to enable poor villages and poor households to escape from poverty in essence and get out of the vicious circle of "helping the poor year after year". On the one hand, special breeding and processing industries can be developed according to the actual conditions in poor villages so that there is a source of income for the family. On the other hand, we should give full play to the role of fiscal funds in leveraging 
credit funds. We actively innovate the mechanism for financial poverty alleviation and development, and actively promote the development of microfinance credit in small amounts in the city, earnestly to enhance the vitality of poverty-stricken villages and poor peasants.

Strengthen the Supervision of Financial Funds. To enable residents who truly meet the standards of poor households to receive timely financial subsidies and effectively prevent fraudulent acquisition of funds, they can not do without supervision at all levels of the village, town and city levels. We will actively carry out surveys on the poverty situation in villages or households and establish cards. We will strictly scrutinize the procedures for reporting information on poor households according to the rules, and carry out dynamic management of the information. We will publicize the results in a timely manner, and give full play to the power of the masses so that villagers can exercise their own supervision so that we will accurately identify the target groups to ensure that subsidies really be implemented.

Strengthen the efficiency of the use of financial resources. In view of the existing defects in the poverty alleviation system, under the new concept of precise poverty alleviation proposed by the Central Party Committee, we must make up and perfect the original system of poverty alleviation institutions according to specific conditions. With the system to ensure that special funds for poverty alleviation aimed at poor residents, in the right direction, for illegal use of poverty alleviation funds to increase efforts to investigate and deal with the situation, to avoid capital "Zhang Guan Li Dai" for other image of the phenomenon. Therefore, the author believes that a corresponding public financial disclosure system should be established to publicize the use of poverty-alleviation projects and the use of funds to the public and solicit opinions and suggestions from the general public so as to ensure the effectiveness of the project construction and make the special funds for finance play an effective role in helping the poor Help role.

\section{Acknowledgements}

Heilongjiang Philosophy and Social Sciences Planning Project: Research on the Financial Support for the Industrial Transformation and Upgrading of Longjiang in the New Situation(Project No. 16JYA01)

\section{References}

[1] B.Y. Pan: Finance Economy, (2016) No.8, p.14. (In Chinese)

[2] D.L. H, Y. OuYang and X.H. Zhou: Hunan Agriculture, (2016) No.16, p.36. (In Chinese)

[3] B.Q. Weng: Gansu Agriculture, (2016) No.21, p.1. (In Chinese)

[4] W.J. Yang: Qinghai Social Sciences, (2016) No.3, p.138. (In Chinese)

[5] Peng L, Xiaoping Z. Social Stratification and Cooperative Behavior in Spatial Prisoners'

Dilemma Games [J]. PLOS ONE, 2015, 10(7):e0131005. (In Chinese) 